\title{
Post harvesting Onion Storage Methodology Using IOT
}

\author{
Mokshi Vyas $^{1}$, Rutuja Gore ${ }^{2}$, Manali Misal ${ }^{3}$, Sneha Jagtap ${ }^{4}$, Prof. S.V. Todkari ${ }^{5}$ \\ Student, IT Dept, JSPM College, Pune, India ${ }^{1,2,3,4}$ \\ Guide, IT Dept, JSPM College, Pune, India ${ }^{5}$
}

\begin{abstract}
Internet of Things plays a vital role in smart agriculture monitoring system. Smart farming is an emerging concept, because IoT sensors are capable of providing information about their fields. Wireless Sensor Networks are performing a key role in different applications such as healthcare, agriculture, environment monitoring, home automation. Monitoring environmental factors is the major factor to improve the yield of the crops. The main feature of this paper is monitoring temperature and humidity in agricultural field. This monitoring is done by using sensors and sending the message to the farmer. The main purpose of paper is to propose a grid system onion storage methodology which will help to reduce onion degradation due to temperature and humidity. If in the storage of onions, one of the onion starts degradation then this system will send the message to the farmer. This will help to improve yield better quality onion and save the farmers from the major economic loss.
\end{abstract}

Keywords: Wireless Sensors Network, Sensors, Climate, Agricultural Productivity, Internet of Things

\section{INTRODUCTION}

The Internet of Things (IoT) is a computing concept that describes the idea of everyday physical objects being connected to the internet and being able to identify themselves to other devices. Internet of Things focuses on connection of different sensors to physical object and transmits information to internet. It has a significant role in the field of agriculture in terms of control and protection, providing real time information and communicating with the physical world. onion storage methodology to reduce its degradation. focuses on studying various monitoring systems that have been designed and implemented in the field of agriculture. Internet of Things plays a important role in smart agriculture monitoring system. Smart farming is an emerging concept, because IoT sensors are capable of providing information about their fields. The main feature is monitoring temperature and humidity in agricultural field. This monitoring is done by using sensors and sending the message to the farmer. The main purpose is to propose a grid system onion storage methodology which will help to reduce onion degradation due to temperature and humidity. If in the storage of Onions, one of the onion starts degradation then this system will send the message to the farmer. This will help to improve yield better quality onion and save the farmers from the major economic loss.

\section{LITERATURE SURVEY}

\section{Applications of WSN in Agricultural Environment Monitoring Systems .[1]}

The Wireless Sensors Network (WSN) is nowadays widely used to build decision support systems to solve many realworld problems. One of the most interesting fields having an increasing need of decision support systems is agricultural environment monitoring. Agricultural environment monitoring has become an important field of control and protection, providing real-time system and control communication with the physical world. An intelligent and smart WSN system can collect and process large amount of data from the beginning of the monitoring and manage air quality, soil conditions, to weather situations. The proposed system collects and monitors information related to the growth environment of crops outside and inside greenhouses using WSN sensors and CCTV cameras. The temperature and humidity sensors are developed in-house and both sensors are very reliable. Furthermore, the system allows automatic control of greenhouse environment remotely and thus improves the productivity of crops. This paper presents hardware architecture, system architecture and software process control of the agriculture environment monitoring system.

\section{Rice Crop Monitoring System - A Iot Base Machine Vision Approach .[2]}

In India farmers lose 37Xanthomonasoryzaepv(XOO) every year.To reduce the spread of infection and to increase the production of the crop the paper Rice crop monitoring system-An IoT machine vision approach is beneficial. It detects the infected part of the crop and takes immediate remedy by spraying the pesticide automatically on the infected area of the specific microbial affected plant by tracking the exact location and taking the periodic images of the crop for large 
Vol. 8, Issue 5, May 2019

area. This system reduces the wastage of pesticides to the entire farm and also reduces the human effort. In this system the proposed work is to monitoring system for the rice crop by using both hardware and software approaches which are implemented in raspberry pi as well.

Onion Postharvest Quality Assessment with X-Ray Computed Tomography A Pilot Study .[3]

Onions are of major importance to the agriculture sector with an estimated world-wide production of 78.5 million metric tons. Out of these, approximately 3.7 million tons are ascribed to the United States with an aggregated farm gate value of USD 1.15 billion [1]. Onions are susceptible to bacterial and fungal infections, most critically during the short harvest period from April to May. To allow for a year-round supply, onions are stored in controlled atmosphere facilities. Infected onions, even if no decay or damage is visible, put the entire harvest in the storage facility at risk. Early detection of bacterial and fungal infections is therefore highly desirable. In this pilot study, we used a low-cost, custom-built x-ray computed tomography (CT) scanner to obtain cross-sectional images of yellow sweet Granex onions (Allium cepa) that were inoculated with pathogens. CT images were analyzed for features that could potentially be used to detect signs of pathogen-related decay in the early stages of infection. The long-term vision is to use CT scanners in an onion packinghouse to perform automated postharvest quality assessment.

A Scalable Machine Learning System for Pre-Season Agriculture Yield Forecast Igor Oliveira, Renato L. F. Cunha, Bruno Silva, Marco A. S. Netto.

Yield forecast is essential to agriculture stakeholders and can be obtained with the use of machine learning models and data coming from multiple sources. Most solutions for yield forecast rely on NDVI (Normalized Difference Vegetation Index) data, which is time-consuming to be acquired and processed. This system provides significantly useful results by the exempting the need for high-resolution remote-sensing data and allowing farmers to prepare for adverse climate influence on the crop cycle. In our studies, we forecast the soybean and maize yields for Brazil and USA, which corresponded to $44 \%$ of the world's grain production in 2016. Results show the error metrics for soybean and maize yield forecasts are comparable to similar systems that only provide yield forecast information in the first weeks to months of the crop cycle.

\section{PROPOSE SYSTEM}

In Proposed system we are analysing To design and implement the Proposed post harvest onion storage methodology to reduce its degradation. In this project we are going to build a Onion Harvesting detection using Arduino,LM35 Temperature Sensor ,Humidity Sensor , Gas sensor and GSM Module. The objectives of this Quality of Onion using ARDUINO is to sense the Ammonia Gas, Temperature , Humidity help of LM35 temperature sensor, Gas Sensor MQ 137, and send SMS alerts to mobile numbers stored inside the ARDUINO program if onion quality is etected using GSM.

\section{SYSTEM ARCHITECTURE}

Following diagram is our system's architecture diagram:

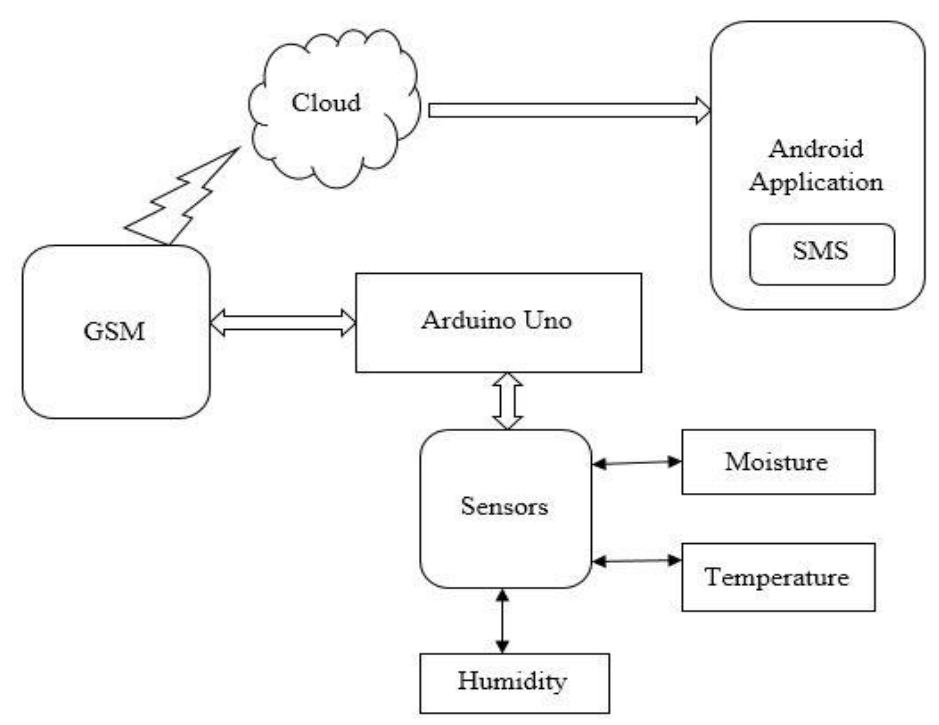

Figure 1: system architecture 


\section{International Journal of Advanced Research in Computer and Communication Engineering}

Vol. 8, Issue 5, May 2019

\section{METHODOLOGIES}

In that some method are used for display the result. So, in that the Android application using the Wi-Fi they are interfacing the hardware values.In that some Hardware are used like Temperature sensor, Humidity sensor, moisture sensor, Arduino, Wi-Fi -ESP8622, weather temperature sensor.

A temperature sensor is a device,that provides for temperature measurement through an electrical signal. A thermocouple $(\mathrm{T} / \mathrm{C})$ is made from two dissimilar metals that generate electrical voltage in direct proportion to changes in temperature.

The LM35 is one kind of commonly used temperature sensor that can be used to measure temperature with an electrical $\mathrm{o} / \mathrm{p}$ comparative to the temperature (in ${ }^{\circ} \mathrm{C}$ ). It can measure temperature more correctly compare with a thermistor. This sensor generates a high output voltage than thermocouples and may not need that the output voltage is amplified. The LM35 has an output voltage that is proportional to the Celsius temperature. The scale factor is $.01 \mathrm{~V} /{ }^{\circ} \mathrm{C}$.

Humidity sensor is Working voltage $3.3 \mathrm{~V}-5 \mathrm{~V}$ Humidity measurement range 20 percent -95 percent, humidity measurement error +-5 percent.Temperature measurement range $0-50$, measurement error +-2 degrees.DHT11 digital temperature and humidity sensor module is a composite Sensor contains a calibrated digital signal output of the temperature and humidity.

Arduino is an open-source electronics platform based on easy-to-use hardware and software. Arduino boards are able to read inputs - light on a sensor and turn it into an output - activating a motor, turning on an LED, publishing something online.

\section{RESULT}

\begin{tabular}{|c|}
\hline 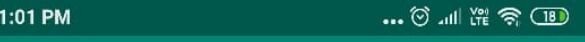 \\
\hline Onion Detection \\
\hline My History of Sms \\
\hline $\begin{array}{l}\text { SMS From: }+917887648427 \\
\text { Mycstatus:onoffk } \\
\text { Latitude: } 18.466850 \\
\text { Longitude: } 73.857772\end{array}$ \\
\hline $\begin{array}{l}\text { SMS From: +917887648427 } \\
\text { Mycstatus:onoffk } \\
\text { Latitude: } 18.466850 \\
\text { Longitude: } 73.857772\end{array}$ \\
\hline $\begin{array}{l}\text { SMS From: }+917887648427 \\
\text { Mycstatus:onoffk } \\
\text { Latitude: } 0.000000 \\
\text { Longitude: } 0.000000\end{array}$ \\
\hline $\begin{array}{l}\text { SMS From: }+917887648427 \\
\text { Mycstatus:onoffk } \\
\text { Latitude: } 0.000000 \\
\text { Longitude: } 0.000000\end{array}$ \\
\hline $\begin{array}{l}\text { SMS From: }+917887648427 \\
\text { Mycstatus:onoffk } \\
\text { Latitude: } 0.000000 \\
\text { Longitude: } 0.000000\end{array}$ \\
\hline $\begin{array}{l}\text { SMS From: }+917887648427 \\
\text { Mycstatus:onoffk }\end{array}$ \\
\hline
\end{tabular}


Vol. 8, Issue 5, May 2019

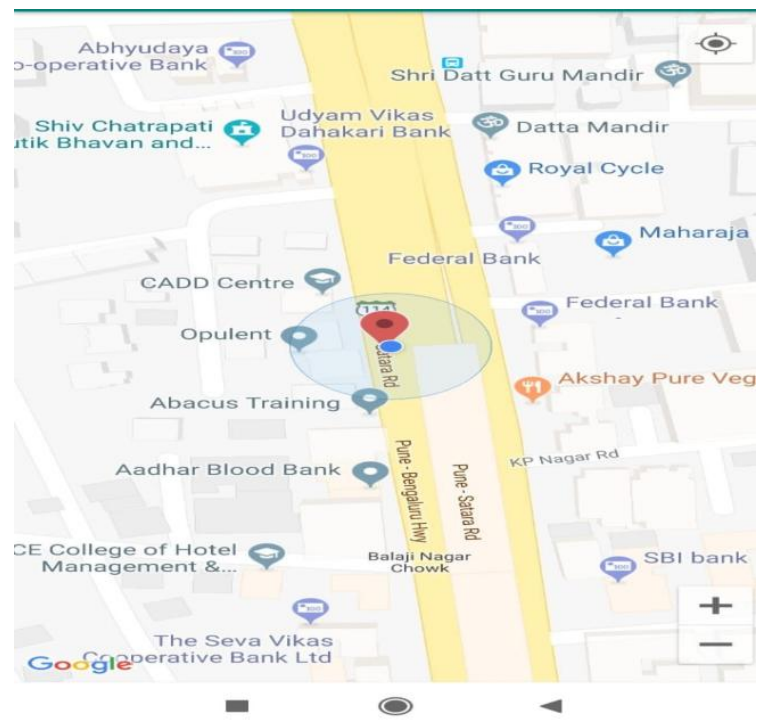

VII. CONCLUSION

For fresh onions (sample), the output readings seems to be controlled (within the range) according to Indian environment. We started rottening process and performed the same procedure and we observed that the values of parameters are getting increased rapidly. In India considering erratic environment monitoring temperature and various parameters are important. In addition to that rain is also a considerable parameter. By using this system, one can monitor all the desired parameters and provide maximum controlled onion quality. This system will provide notification to owner (farmer) by mean of audio, display and wireless message(sms).it is low cost, low maintenance and easy to install, anyone can afford it. We can have real time data which can be used for future research/purposes

\section{REFERRENCES}

[1]. Md. Tahmid Shakoor, Karishma Rahman, Sumaiya Nasrin Rayta, Amitabha Chakrabarty, "Agricultural Production Output Prediction Using Supervised Machine Learning Techniques", IEEE, 2017.

[2]. S.Veenadhari, Dr. Bharat Misra, Dr.CD Singh, "Machine learning approach for forecasting crop yield based on climatic parameters", International Conference on Computer Communication and Informatics (ICCCI -2014), Jan. 03 -05, 2014.

[3]. Nishit Jain, Amit Kumar, Sahil Garud, Vishal Pradhan, Prajakta Kulkarni, "Crop Selection Method Based on Various Environmental Factors Using Machine Learning”, International Research Journal of Engineering and Technology (IRJET), Volume: 04 Issue: 02 , Feb -2017.

[4]. Igor Oliveira, Renato L. F. Cunha, Bruno Silva, Marco A. S. Netto, "A Scalable Machine Learning System for Pre-Season Agriculture Yield Forecast", 14th IEEE eScience, https://arxiv.org/abs/1806.09244

[5]. R. Nageswara Rao, B.Sridhar," Iot Based Smart Crop-Field Monitoring and Automation Irrigation System", IEEE Second International Conference on Inventive Systems and Control (ICISC), 2018.

[6]. Ekata Ghadage, Vibhavari Kharate, Parnika Mane, Samruddhi Pimpale," Smart Irrigation and Crop Planning System:using Arduino Microcontroller", International Journal of Advanced Research in Computer and Communication Engineering, Vol. 6, Issue 1, January 2017,DOI 10.17148/IJARCCE.2017.6186. 